\title{
MOBILITY BOX: A DESIGN RESEARCH METHODOLOGY TO EXAMINE PEOPLE'S NEEDS IN RELATION TO AUTONOMOUS VEHICLE DESIGNS AND MOBILITY BUSINESS MODEL
}

\author{
S. Wolff ${ }^{1, \otimes}$, J. Auernhammer ${ }^{2}$, F. Schockenhoff ${ }^{1}$, C. Angerer ${ }^{1}$ and M. Wittmann ${ }^{1}$ \\ ${ }^{1}$ Technical University of Munich, Germany, ${ }^{2}$ Stanford University, United States of America \\ $\square$ sebastian.wolff@tum.de
}

\section{Abstract}

The future focus of research in the automotive sector will be on automation and data-driven technologies. These technologies provide new services and values to customers, owners and other stakeholders in mobility. We propose a wizard-of-oz like method to evaluate future user needs and redesign the current approach of vehicle development. The mobility box provides a modular and extendable framework to merge user centred design with vehicle data acquisition. This enables the design of services and properties for unknown mobility concepts.

Keywords: user experience, user-centred design, characteristics and properties, experience design

\section{Introduction}

Traditionally, people bought, owned and used an automotive vehicle for their mobility need. This is changing due to new technologies such as autonomous driving and new mobility services. The purchaser, owner, operator and user are different people or businesses. Companies such as Uber, Lyft in the US, Grab in Southeast Asia, Ola in India and Didi in China and Australia provide mobility without owning a vehicle. The combination of new mobility services and technologies offer new mobility solutions for people, particularly in urban environments. One of the biggest questions for companies in the mobility sector is what will the mobility experience that people value be?, what novel business model will succeed? and how should the vehicle look like to fulfil this experience?. To answer these questions, activities as follows are required: 1) Discover needs of people and create meaningful experiences, 2) Evaluate technological possibilities and 3) Find viable business models.

The current approaches of vehicle development, business model design or human-interaction design examine these questions in isolation. Therefore, this paper outlines and discusses a design research methodology that allows to analyze new human experiences in relation to vehicle requirements and business model activities. This methodology has been termed the Mobility Box. The Mobility Box is a box in which various user experiences can be designed and evaluated. The Box can be mounted in a vehicle that resembles an autonomous vehicle and put into real-world context to observe and identify people's needs, behavior and experiences in these new mobility services. The box allows to design and experiment different experiences from a conference room for commutes to office or a fan shop integrated in the mobility service on the way to an event such as a concert or a sporting event. The Mobility Box allows to experiment rapidly and iteratively different experiences and aims to discover 
what people value?, what technological requirements are vital to produce the experience? and what business model would allow to sustain the mobility service at scale?. This paper outlines a concept of a design research methodology in the mobility sector.

\section{Perspectives on vehicle concept development}

Vehicle concept (VC) development is in a changing period due to new service models and technological opportunities. This section discusses briefly current developments and concludes that there is a need for integrating a Human-centred Design (HCD) approach into the development of VCs.

\subsection{Autonomous vehicle concepts}

In automated vehicles, the interior will have a much higher degree of freedom than today's VCs (Tzivanopoulos et al., 2014). Additionally, automation of driving of the level 4 and, in particular level 5 (SAE, 2018) will enable users to perform secondary activities as they do not have to focus on driving task. This offers new opportunities for VCs, which is researched by automotive manufactures and university. They investigate how future VCs can look like. A particular aspect of this research is the different types of bodywork as illustrated in Figure 1.

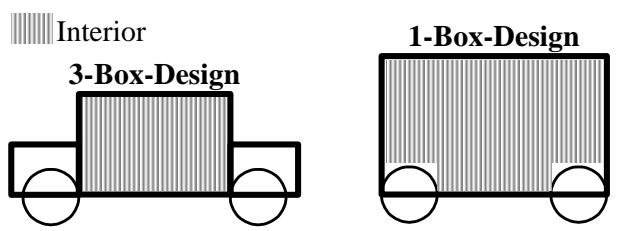

Figure 1. Types of bodywork

The VC Audi Aicon is a 3-box-design that resembles current VCs (Schloßmacher, 2017). The use case for this concept is based on luxury, long haul, and privately owned vehicle. A different VC that is a 1Box-Design is the VW Sedric (Volkswagen, 2018). The 1-Box-Design provides a higher ceiling and more interior space (Winner and Wachenfeld, 2015, p. 273). This allows new concept designs and novel use cases. It's designed for shared and short travels in urban environments. To vary the use case of the vehicle easily during the development process, the UNICARagil proposes the approach of scalable and modularized vehicle structures (Woopen et al., 2018). These are spited in a scalable driving platform with all components to fulfil the driving function and an add-on transport module, which allows different specified interior concepts. Such VCs provide new opportunities for new user experiences as well as new mobility service business models.

\subsection{Vehicle concept development}

In today's VC development process, user and technological requirements are taken into account through a three step loop as illustrated in Figure 2. They incorporate customer-relevant properties, technical characteristics and VC (Fuchs and Lienkamp, 2013; Wiedemann et al., 2012):

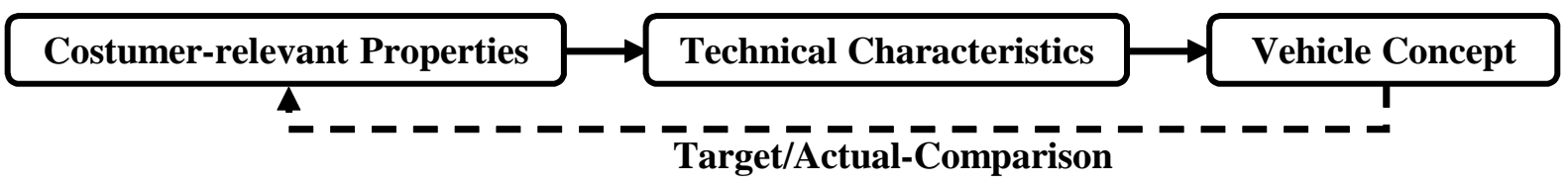

Figure 2. Current Vehicle concept development process

The customer-relevant properties specify the vehicle's behavior and the customer's requirements for the VC. They outline the customers attached values in relation to their purchase decision (Helm et al., 2017, p. 6). For example, the time for the acceleration from $0-100 \mathrm{~km} / \mathrm{h}$ may be a traditional customer value. These customer-relevant properties are translated into technical characteristics (Weber, 2007). In the acceleration example, the engine torque, the engine power or the transmission ratio result among other properties from the desired acceleration which is assumed to be relevant for the customers purchasing decision. These 
technical characteristics lead to the selection of the components, which forms the VC. A comparison of the actual properties of the developed $\mathrm{VC}$ and the target properties enables loops to optimize the result.

\subsubsection{Objectivation of customer-relevant properties}

In this process, the objectification of the customer-relevant properties is an essential step. It translates customer-relevant properties description into technical values and concepts as necessary input for the physical simulations (Wiedemann et al., 2012). Most of conventional customer-relevant properties already exist in a quantitative value due to long history of objectifying subjective parameters in the automotive sector (Heißing and Brandl, 2002). This is based on the behavior and tasks of the driver, who is the dominant occupant in the vehicle in traditional models of buying and owning a vehicle. This will fundamentally change with autonomous VCs. Interior and driving style related properties will become more important (Becker et al., 2018). Therefore, an increased focus is on the comfort of the passengers. Comfort parameters are subjective as every person assesses it differently. The subjective comfort parameters have been investigated in several studies. Hartwich et al. (2018) examined the correlation between the age, the familiar driving style and the comfort level of passengers. In specific maneuvers, Bellem et al. (2018) and Festner et al. (2017) investigate possible quantitative parameters to describe the comfort level of driving styles. These studies are designed to correlate parameters in a driving maneuver. A holistic result for real-world drives is not achieved, as the passengers' overall experience (secondary activities, past trajectories, interior design etc.) is not considered.

These studies are based on traditional automotive VCs of product ownership. In these models, roles are producers and customers (purchaser, owner and user in one person). In new VCs and mobility services, the customer is no longer one person. From the producer's perspective, the customer can be divided into roles including purchaser, operator and user. New mobility models are the result of different combinations of these roles that enable a business model. An example are the mobility providers discussed in the introduction section. In these models a driver (operator) rents a vehicle from a car rental agency (purchaser) and drives another person who orders a ride (user). These mobility service business models need a new approach in the VC development. A valuable approach is humancentred design (HCD) as it examines people's needs in specific contexts.

\subsubsection{Human-centred design in automotive development}

HCD has been developed in particular in human-vehicle interactions. Such studies investigated the interaction between pedestrians and autonomous vehicles (Risto et al., 2017; Rothenbücher et al., 2015) and driver behavior and interactions with autonomous vehicles (Mok and Ju, 2014).

HCD in automotive development is not particularly focusing on customer-relevant properties. Customer-relevant properties are a technology-centric view of how the vehicle should catch customer attention (styling), how seating provides a certain comfort (ergonomics) or how much storage room it provides (practicality) to name a few (Ziemann, 2007, pp. 138-153). In contrast, HCD centers the person and people's needs, experiences and behavior in the design. For example, if people commute every day to work, their needs may be utilizing this time for work tasks such as answering emails or reading newspapers, the automobile may not be the solution or a solution that incorporates risks such as safe driving. HCD incorporates researching and finding human needs in cultural and technological contexts to design, for example interaction concepts (Martelaro and Ju, 2017a, 2017b). HCD focuses on the needs, experiences and behavior of people in specific-contexts and how a specific design can fulfil such needs, enable specific experiences and facilitate certain human behavior. This follows the philosophy by McKim (2016) that every design is a response to a human need.

A common methodology in HCD in automotive development is Wizard-of-Oz prototyping. It allows to experiment human behavior, experiences and interactions without committing to expansive developments or waiting until the technological readiness allows to examine vehicle-human interactions with potential future design solutions. It allows today to examine what are people's experiences with potential future vehicle designs. This learning can be utilized to not only design the look and feel of the vehicle, but what kind of $\mathrm{VC}$ has the potential to be meaningful in specific human contexts. It also allows to examine if business models (BM) such as service-subscription or targeted advertisements are accepted by people. To be able to research and capture human needs and experiences in relation to VCs 
including technological functions and mobility service BM aspects, a new integrated methodology is needed. This paper outlines a design research methodology, which has been termed the mobility box.

\subsection{Motivation}

As people's needs and experiences and consequently "subjective requirements" will gain importance for autonomous VCs, HCD can help to translate human needs, experiences and behavior into technological requirements. Currently, new mobility concepts are indeed anticipated (e.g. DB Ioki or VW Moia), but they are difficult to validate and test with respect to (future) user needs. With the current technology-focused development processes, the early consideration of future needs is only partially possible or not possible at all. Consequently, it is required to integrate HCD into vehicle development. Furthermore, service business model considerations need to be taken into account to enable services that are meaningful and work at scale. HCD, vehicle technology development and business model considerations need to be integrated to develop new user experiences provided by new vehicle design that generate innovative mobility concepts. Our motivation is to formulate and develop an integrated design research methodology that incorporates human needs, experiences and behaviors through HCD and its implication for the VC and mobility service concept (business model). The main research questions of this paper are as follows:

1. What methodology allows to examine (future) needs of autonomous vehicle users?

2. How can (technical) characteristics and business model opportunities be derived from the identified needs?

3. How can they be translated into technological requirements and business model opportunities?

\section{Mobility Box}

The Mobility Box is a box that represents a space for experimentation and prototyping within the interior of a vehicle. It is an interchangeable box that can be mounted inside a van, minibus and potentially any kind of vehicle with enough space such as a train. Within each box a unique design concept for a specific user experience can be created, prototyped and evaluated. Different themes can be created such as a conference room, gym or business lounge to name a few examples. These themed experiences can be designed by combining elements from topics such as food, leisure or digital as shown in Figure 3.

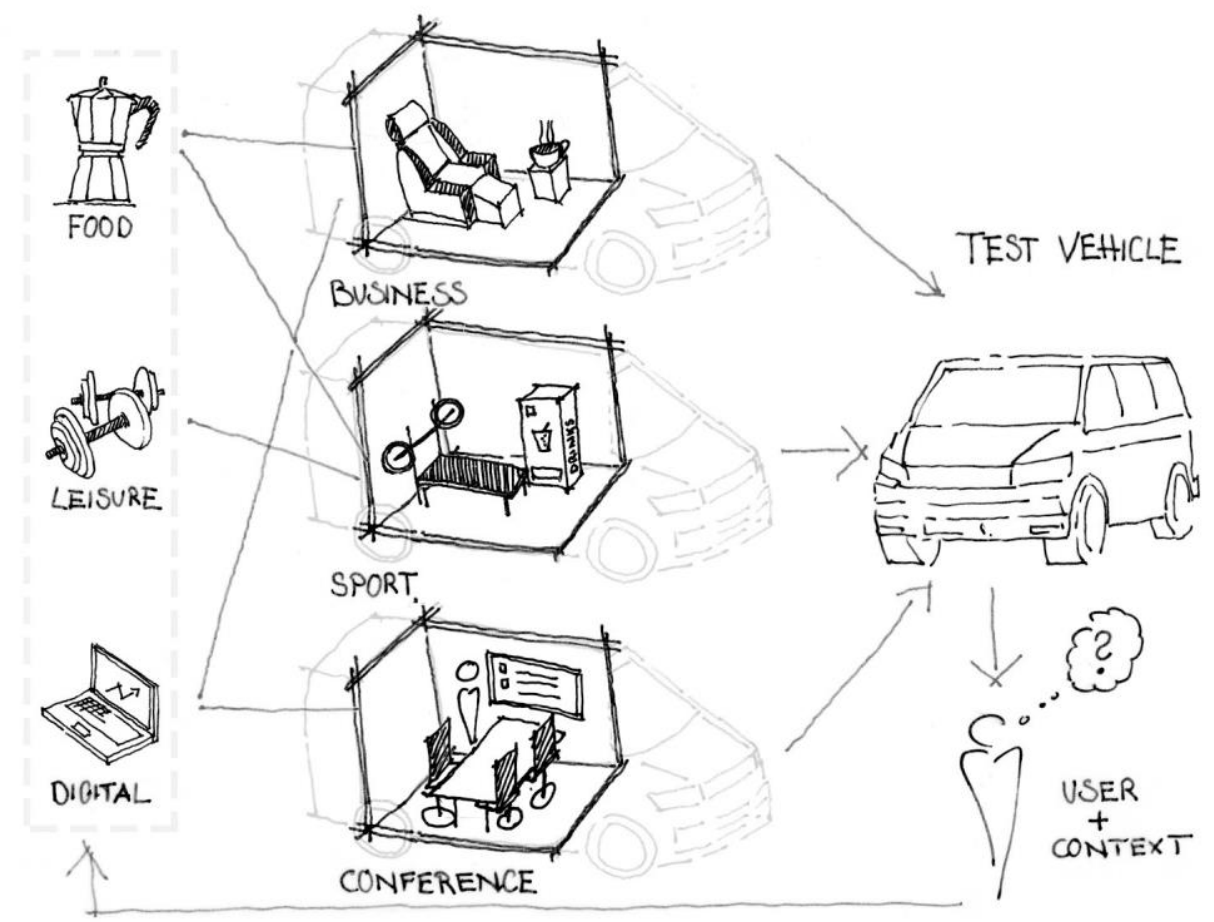

Figure 3. Example of the design research methodology Mobility Box 
A Wizard-of-Oz style experiment simulates an autonomous vehicle and mobility services. The box experiments can be executed in real-world human context. The vehicle that incorporates the box can transport participants while examining the user experience and behavior. The Mobility Box as illustrated in Figure 3 allows to experiment various user experiences in real-world context. Experiments related to specific contexts such as routine commutes from train stations to office during rush hour can be created by placing the test vehicle into the right place at the right time. Other experiments can be designed for human contexts such as sports events, concerts, routine commutes etc.

The Mobility Box allows to rapidly re-designed themes based on observed user behavior to iteratively and creatively design, prototype and evaluate novel user experiences. The Mobility Box allows to examine vehicle properties such as suspension, acoustics or even drivetrains can be tested by exchanging components or the complete vehicle. Additionally, the Mobility Box aims to examine a variety of business models and observe their relation to the designed themes and user experiences. This is illustrated in Figure 4 and elaborated in further detail in this section.

As shown in Figure 4, the three sets of data collection are combined to discover design requirements iteratively and analyze their interrelations. The Mobility Box aims to design and evaluate meaningful experience for people enabled by the technological components and viable business models. This is described in detail in section 3.1 to 3.6.

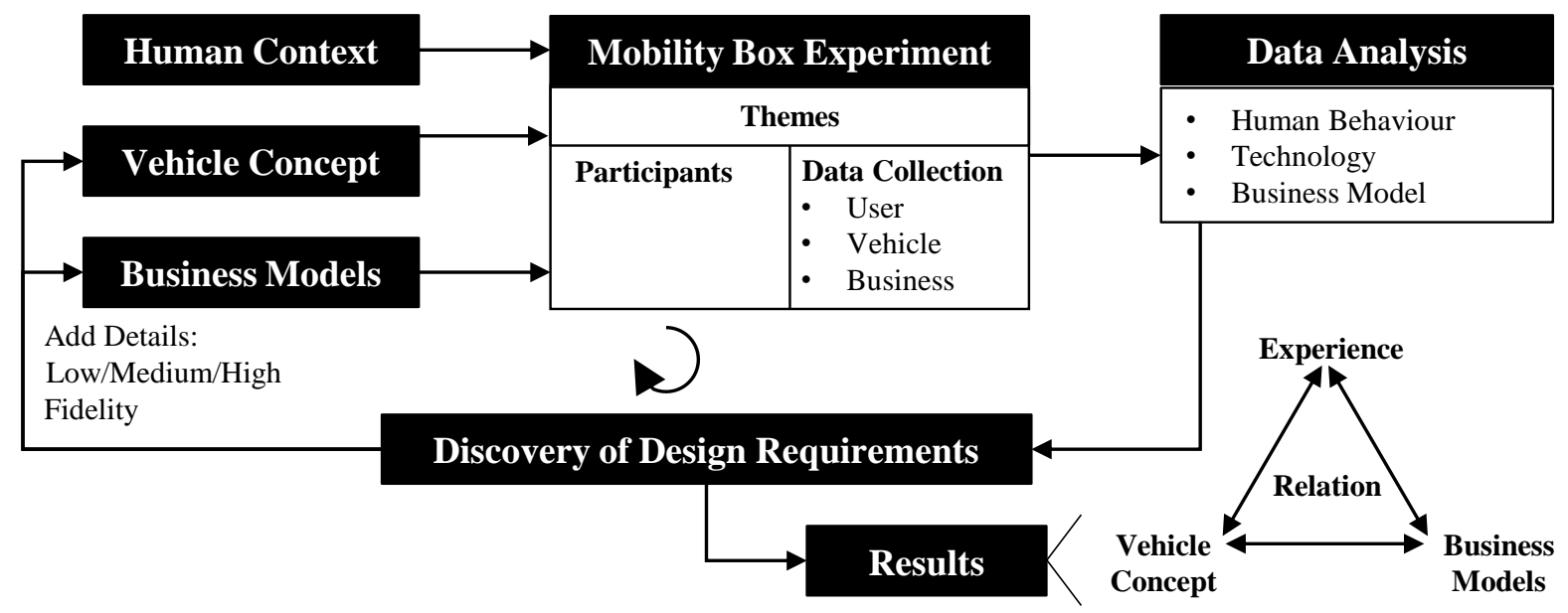

Figure 4. Iterative methodology of the Mobility Box concept and expected results of the study

\subsection{Human context}

The first aspect that needs to be considered is the participants context. This incorporates the cultural context such as shared norms, values, language and attitudes, environmental context such as an urban environment, demography and time-specific events such as rush hours or the Munich Oktoberfest. For example, in an urban environment, during rush hour, in which punctuality is a cultural norm, a large amount of people will arrive at a central train station and have the routine behavior to use other public transport to travel to their office. In this specific human context, what needs do people have and what meaningful experiences could be designed in a mobility service? For designing promising themes as well as knowing when a specific design fulfils people's needs or enable meaningful experiences, it is essential to understand the human context in which the mobility box is executed. Approaches such as ethnography, research on population and observations at specific places and in specific timeframes are useful to understand human context and perceiving human needs (Faste, 1987; Gunn et al., 2014).

\subsection{Vehicle concept}

The conventional view of a $\mathrm{VC}$ is defined as a construct that represents all the formative aspects of the vehicle in an abstract manner (Achleiter et al., 2016, 140f). This includes the component selection and its positioning, design freedoms in autonomous VCs and conventional assembly groups such as interior, exterior, drivetrain and chassis. 
The mobility box represents the interior and its variation and is an essential part of the experiment. The exterior is partly dependent on the mobility box. The mobility box defines the type of bodywork whereas the noise cancelling of the sealing or the door system are technical parameters, which could be varied. The selection and the positioning of all components of the drivetrain should adapt to the needs of the passengers of the specific mobility box. The main components are the engine, the gearbox and the energy storage system, e.g. the battery system. The same steps are necessary for the chassis. Its components, the suspension, the axles and the steering, vary in complexity, comfort and cost levels. In our presented method, the VC element is the engineering design part. The mentioned components with their technical parameters must be connected to the mobility box. Hence, a variation and adaptation of these technical parameters is needed to postulate recommendation of exterior, drivetrain and chassis specification for a given mobility box.

\subsection{Business models}

The Business Model (BM) is an essential aspect in new mobility services. BM research has mainly focused on system-levels of how to do business, main activities of a business and how value is created (Zott et al., 2011). The mobility box aims to experiment in the front-end of the activity chain of the business, the potential customer experience and work backwards from a meaningful experience to design the activity model that allows to build a sustainable BM. Value is created by fulfilling a human need and designing a meaningful experience as discussed by McKim (2016). Therefore, the BM design for the mobility concept is based on the needs, experience and behavior of the participant rather than the BM determining the experience and behavior of people. This means that the first iteration of the mobility box prototype should be free from any business model considerations. Based on the first learnings from the prototype, several aspects can be developed that have implication for the BM. For example, if a meaningful experience during the mobility service is to offer food and drinks several activity system content, structure and governance as described by Zott and Amit (2010) can be thought of such as a driving coffee shop as a franchise model. The BM can be established by sequencing the activity system to enable the reproduction of this experience at scale. This allows to go beyond the obvious mobility business models for the sharing economy as outlined by Cohen and Kietzmann (2014). The mobility box prototype allows to experiment with various service mobility BM ideas in relation to the needs of participants. It is an HCD approach to business model design through examining what people value and work backwards to design the BM.

\subsection{Mobility box experiment}

The Mobility Box experiment incorporates the design of themes, participants in specific humancontext and collection of data. Through iterative design, data can be collected and informs how the theme, $\mathrm{VC}$ and business model can be designed to provide a valuable experience. This is an iterative process of discovering requirements of the future design concept.

\subsubsection{Themes}

Themes are different experiments to examine designed experiences of participants of the Mobility Box. The Mobility Box allows to examine use cases such as sleeping $\&$ relaxing, working $\&$ being productive, eating \& drinking, entertainment as well as beauty, well-being \& fitness as described by Becker et al. (2018). These use cases may not apply and real human needs in specific contexts need to be identified to design a meaningful experience. Therefore, it is necessary to evaluate various experiences. A theme represents a particular designed interior concept and experiment such as business lounge, gym or conference room as illustrated in Figure 3. As people use and misuse their environment in different ways, themes aim to answer which design leads to which experience for a participant.

\subsubsection{Participant}

There are several sample population strategies. A first one is that the sample population of the mobility box prototype is dependent on the human context at a specific event (place and time) such as rush hour at a central train station will determine the participant sample. Another sample population strategy may be purposive sampling of specific participant groups such as top manager 
to experiment a specific mobility service experience for this specific group of people. However, rather than objectifying people into groups based on age, income and status, a more meaningful approach is to base it on needs and behavior. Some top manager may have the need to utilize the time during the mobility service experience to work on specific tasks while others desire to network with others on the same route to office. Examining who desires what and when is part of the needfinding activates of the mobility box prototype to design mobility service experiences for a specific "needs group", people with similar needs. Therefore, identifying for whom is what experience meaningful is part of the iterative prototyping cycle and is a result of examining the human context as described above.

\subsubsection{Data collection}

The data collection aims to capture human needs and experience, vehicle data as well as examine $\mathrm{BM}$ aspects. Human needfinding and experiences can be observed through video and audio recordings as well interviews in context. An successful approach is the Needfinding Machine as elaborated by (Martelaro and Ju, 2017a, 2017b). This approach allows remote observation and interaction prototyping on the road through live video, audio, vehicle data and Wizard of $\mathrm{Oz}$ speech and interfaces. The designer is in the loop with the user and can prototype and explore specific experiences and engage in Needfinding activities such as ethnographic interviews as described by Faste (1987). Experiences and behaviors can be examined through video recordings of facial, vocal and bodily expressions of participants (e.g. Gomez et al., 2006). "Experience prototypes" as described by Buchenau and Suri (2000) allow to experiment and examine human experiences. User-to-user as well as user-vehicle interactions and other behavior can be captured through video data. Other data such as physiological data can be collected by utilizing eyetracking or pulse measurement. The data collection to observe and identify the human needs, experiences and behavior allows to link it to vehicle data as well as data collection relevant for BM design.

Wittmann et al. (2017) proposed and tested a holistic framework to acquire, process and evaluate vehicle fleet test data. The framework allows a scalable solution to record vehicle sensor data either using low-cost smartphones, a flexible OBD-II data logger or highly accurate equipment such as gyro platforms, depending on the target's requirements. For example, it can measure values like, longitudinal speed, 3D acceleration and rotation, the vehicle's engine rpm, noise or temperature. A simple evaluation of the corresponding time series is sufficient for many applications but combining those signals with empirical user feedback gives a meaningful context. In addition, the framework is able to capture the participants spatial mobility behavior.

Therefore, the logging devices additionally capture high frequency GNSS-Data. Based on those measurements, it is possible to derive a detailed analysis along the driven track. For example, influences coming from external impacts (road conditions etc.) can be observed and compared to the feedback of other participants, even if the test vehicle does not drive exactly the same route.

In addition to human experiences and vehicle data collection, data can be collected that is relevant for $\mathrm{BM}$ aspects. For example, in a subscription service BM, price points can be investigated by providing different prices for the same service. Data collection can be accomplished through A/B testing. Another example is experimenting how advertisements during the experience are perceived by people and if an advertisement-based BM is viable. Is a targeted advertisement model enabled by capturing the data of participants a viable option as people's behavior during the service experience indicate to react to specific advertisements? Such data can be collected through behavioral examination as described above. Examining and collecting activities of value creation, a meaningful human experience viable BMs such as service subscriptions, freemium through advertisement or rent or sell shops space within the vehicle can be anticipated.

\subsection{Data analysis}

The collected data of user experiences, vehicle data and BM aspects can be analyzed through various approaches. A selection of collection and analysis methods is shown in Table 1. 
Table 1. Exemplary methods for data collection and analysis

\begin{tabular}{llll} 
Perspective & Objective & Data Collection & Data Analysis \\
\hline Human & Emotional Experience & Video-audio recordings & $\begin{array}{l}\text { Facial expression and voice } \\
\text { signals coding }\end{array}$ \\
& Behaviour & $\begin{array}{l}\text { Body-mounted sensors } \\
\text { (Physiological data) }\end{array}$ & Statistical analysis \\
& Needs & Video-audio recordings & $\begin{array}{l}\text { Categorization scheme; } \\
\text { frequency counts }\end{array}$ \\
& Vehicle Dynamics & $\begin{array}{l}\text { Ethnographic interview (audio } \\
\text { data) }\end{array}$ & $\begin{array}{l}\text { Qualitative coding and text } \\
\text { mining }\end{array}$ \\
\hline \multirow{5}{*}{ Technology } & Torque, Consumption etc. & $\begin{array}{l}\text { Smartphone Sensors, gyro } \\
\text { platform } \\
\text { OBD-II Data Logger }\end{array}$ & Frequency analysis \\
& Mobility Data & GPS/GNSS & $\begin{array}{l}\text { Statistical analysis } \\
\text { Origin-Destination-Matrix }\end{array}$ \\
\hline & Pricing, cash flow, revenue & A/B testing & $\begin{array}{l}\text { Statistical analysis } \\
\text { Categorization scheme; } \\
\text { frequency counts }\end{array}$ \\
& Customer value activities & Video and audio recordings & Themes - user experiences \\
& Complementarity & Video and audio recordings & relationship evaluation
\end{tabular}

The contribution of the methodology is the interlinking of the different data sets to detect patterns in user behavior associated with technological properties as well as business and mobility concepts. The combination of all three sets is the central element of the methodology. Interesting themes in the experiment can be examined from different perspectives. This allows to reveal connections between the three sets which are currently not examined and enables the discovery of technological requirements and business model opportunities based on human needs, experiences and behaviors.

\subsection{Discovery of design requirements}

The data analysis allows to link specific user experiences and behavior to specific VCs as well as to $\mathrm{BM}$ activities. Thus, technological requirements can be discovered, as specific experiences require specific VCs. Similar, specific BM activities need to enable and improve the user experience. If these activities do not create a valued experience, the learning of the Mobility Box may provide insights that allow other BM opportunities to be explored. At the same time, the BM activities as well as the VC including costs of usage or procurement can be interlinked to understand the cost structure of the mobility service that produces a valuable user experience. With each change in the theme, VC or BM activities, a further requirement or combination can be examined and evaluated. This allows to discover the design requirements for all three aspects iteratively. With a better understanding of the requirements, the fidelity of the prototype can be increased. This allows to iteratively develop the $\mathrm{VC}$, user experience and $\mathrm{BM}$ activity system towards a truly innovative mobility service.

\subsection{Ethical considerations and safety regulations}

It is important to take several ethical considerations into account as it is good practice with any human subject research. Designers and design researchers have the responsibility to minimize the risk of harm to the participants. Therefore, every experiment needs to evaluate beforehand to assess risk of harm and minimize it.

Furthermore, it is necessary to comply with applicable law and regulation. The prescribed safety devices, such as safety belts, and regulations, such as compulsory belting, must be considered in the design of the experiment. During the first iterations, however, the experiment can be carried out in closed rooms under controlled conditions to ensure the safety of the participants and the environment. 


\section{Discussion and conclusion}

For the design of meaningful mobility solutions, it is essential to focus the development process on people's needs and experiences. The proposed design research methodology therefore merges HCD with technical vehicle and BM development. The data driven analysis of the three disciplines enables the design of holistic concepts. The iterative approach facilitates the discovery of new design requirements, while fidelity increases in relation to user needs. The possible use of the methodology covers all stages from early concept to advanced product development. Consequently, the required level of detail depends on the user's satisfactory level and the desired results by utilizing this methodology.

The approach anticipates user needs and thus the design for future vehicle, mobility and business concepts. It is a different approach than the traditional customer-relevant properties, technical characteristics and VC loop in VC development. The approach enables out-of-the box solutions in a box. For example, an integrated franchised coffee shop during rush hours or a fan shop at sports events.

The result of the study can help automotive companies to innovate VCs and has the potential to foster entrepreneurial activities. When the user's needs and behaviors are better understood within specific human context, themes can be designed to create valuable experiences that can lead to more sustainable mobility solutions. We expect substantial results from the application of the methodology, as the individual methods and processes utilized have already been successfully applied in other studies.

The ambition is to develop the proposed methodology and publish the findings of various experiments. In the first stage, several themes will be designed. A first prototype will be built in real-world context to examine the key challenges of the proposed methodology. As mentioned before, the campuses of universities could serve as closed environments for the first iterations. With advancing iterations, the human context will be extended to urban commuting in metropoles. The knowledge gained with this design research approach about user behavior that determines design requirements can combine and advance research in the field of HCD, vehicle technology and business model development. With this concept paper, which outlined the Mobility Box as a design research methodology the authors invite industry partners and research institutions to collaborate and reinvent mobility.

\section{Contribution}

S. W.: Idea, Concept; J. A.: Idea, Concept, Business Model Design, HCD; F. S.: Concept, Autonomous VC, VC Development; C. A.: Idea, Concept; M. W.: Idea, Concept, Vehicle Data Collection

\section{References}

Achleiter, A. et al. (2016), "Formen und neue Konzepte", In: Pischinger, S. and Seiffert, U. (Eds.), Vieweg Handbuch Kraftfahrzeugtechnik, ATZ/MTZ-Fachbuch, Springer Fachmedien, Wiesbaden, pp. 131-251.

Becker, T. et al. (2018), Enabling the Value of Time: Implikationen für die Innenraumgestaltung autonomer Fahrzeuge, Fraunhofer IAO, Stuttgart.

Bellem, H. et al. (2018), "Comfort in automated driving. An analysis of preferences for different automated driving styles and their dependence on personality traits", Transportation Research Part F: Traffic Psychology and Behaviour, Vol. 55, pp. 90-100.

Buchenau, M. and Suri, J.F. (2000), "Experience prototyping”, In: Designing interactive systems: Processes, practices, methods, and techniques, ACM, New York City, pp. 424-433.

Cohen, B. and Kietzmann, J. (2014), "Ride On! Mobility Business Models for the Sharing Economy", Organization \& Environment, Vol. 27 No. 3, pp. 279-296.

Faste, R.A. (1987). "Perceiving Needs", SAE Technical Paper Series, SAE.

Festner, M., Eicher, A. and Schramm, D. (2017), "Beeinflussung der Komfort- und Sicherheitswahrnehmung beim hochautomatisierten Fahren durch fahrfremde Tätigkeiten und Spurwechseldynamik", 11. Workshop Fahrerassistenzsysteme und automatisertes Fahren, pp. 63-73.

Fuchs, J. and Lienkamp, M. (2013), "Technologie und Architektur für Elektrifizierte Fahrzeuge", ATZ Automobiltechnische Zeitschrift, Vol. 115 No. 3, pp. 164-170.

Gomez, R., Popovic, V. and Bucolo, S. (2006), "Emotional driving experiences: An opportunity for future technology", Proceedings from the 5th Conference on Design and Emotion.

Gunn, W., Otto, T. and Smith, R.C. (2014), Design anthropology: Theory and practice, Bloomsbury, London.

Hartwich, F., Beggiato, M. and Krems, J.F. (2018), "Driving comfort, enjoyment and acceptance of automated driving - effects of drivers' age and driving style familiarity”, Ergonomics, Vol. 61 No. 8, pp. 1017-1032. 
Heißing, B. and Brandl, H.J. (2002), Subjektive Beurteilung des Fahrverhaltens, Vogel, Würzburg.

Helm, S., Günter, B. and Eggert, A. (2017), Kundenwert: Grundlagen - Innovative Konzepte - Praktische Umsetzungen, Springer Fachmedien, Wiesbaden.

Martelaro, N. and Ju, W. (2017a), "The Needfinding Machine", Companion of the 2017 ACM/IEEE International Conference on Human Robot Interaction, Vienna, Association for Computing Machinery, pp. 355-356.

Martelaro, N. and Ju, W. (2017b), "WoZ Way", Companion of the 2017 ACM Conference on Computer Supported Cooperative Work and Social Computing, Portland, ACM, pp. 21-24.

McKim, R. (2016), "Designing for the Whole Man", In: Arnold, J.E. (Ed.), Creative engineering, pp. 198-217.

Mok, B. and Ju, W. (2014), "The Push vs Pull of Information between Autonomous Cars and Human Drivers", 6th International Conference on Automotive User Interfaces and Interactive Vehicular Applications Automotive UI, Seattle, ACM Press, pp. 1-5.

Risto, M. et al. (2017), "Human-Vehicle Interfaces: The Power of Vehicle Movement Gestures in Human Road User Coordination", 9th International Driving Symposium on Human Factors in Driver Assessment, Training, and Vehicle Design: driving assessment, Manchester Village, University of Iowa, pp. 186-192.

Rothenbücher, D. et al. (2015), "Ghost driver", 7th International Conference on Automotive User Interfaces and Interactive Vehicular Applications, Nottingham, Association for Computing Machinery, pp. 44-49.

SAE (2018), SAE J3016:2018, Taxonomy and Definitions for Terms Related to Driving Automation Systems for On-Road Motor Vehicles, SAE International, Warrendale.

Schloßmacher, J. (2017), Concept Car Audi Aicon - autonom auf Zukunftskurs. Available at: https://www.audimediacenter.com/de/pressemitteilungen/concept-car-audi-aicon-autonom-auf-zukunftskurs-9332 (accessed 25 November 2019).

Tzivanopoulos, T. et al. (2014), “Analysis of new freedoms in future vehicle interiors", 14. Internationales Stuttgarter Symposium: Automobil- und Motorentechnik, Springer Vieweg, pp. 1475-1488.

Volkswagen, A.G. (2018). SEDRIC: Das Auto der Zukunft zum Anfassen. available at: https://www.volkswagenag .com/de/news/stories/2018/02/sedric-the-future.html (accessed 25 November 2019).

Weber, C. (2007), 'Looking at 'DFX' and 'Product Maturity' from the Perspective of a New Approach of Modelling Product and Product Development Processes", 17th CIRP Design Conference, Nantes, Springer, pp. 85-104.

Wiedemann, E., Meurle, J. and Lienkamp, M. (2012), "Optimization of Electric Vehicle Concepts Based on Customer-Relevant Characteristics", SAE 2012 World Congress and Exhibition, Detroit, SAE.

Winner, H. and Wachenfeld, W. (2015), "Auswirkungen des autonomen Fahrens auf das Fahrzeugkonzept", In: Maurer, M. (Ed.), Autonomes Fahren: Technische rechtliche und gesellschaftliche Aspekte, Springer Vieweg, Berlin, pp. 265-285.

Wittmann, M. et al. (2017), "A holistic framework for acquisition, processing and evaluation of vehicle fleet test data", 20th International Conference on Intelligent Transportation Systems, Yokohama, IEEE, pp. 1-7.

Woopen, T. et al. (2018), "UNICARagil - Disruptive modulare Architektur für agile, automatisierte Fahrzeugkonzepte", Aachener Kolloquium, Vol. 27, Aachen, RWTH Aachen University.

Ziemann, A. (2007), Zielsystemmanagement für die Produktentstehung von PKW, [PhD Thesis], Technical University of Munich.

Zott, C. and Amit, R. (2010), "Business Model Design: An Activity System Perspective”, Long Range Planning, Vol. 43 No. 2-3, pp. 216-226.

Zott, C., Amit, R. and Massa, L. (2011), “The Business Model: Recent Developments and Future Research”, Journal of Management, Vol. 37 No. 4, pp. 1019-1042. 